\title{
Therapeutic effect of simultaneous intravitreal dexamethasone and aflibercept on diabetic macular edema
}

\author{
Tai-Chi Lin ${ }^{1,2} \cdot$ Yu-Chien Chung ${ }^{3,4,5} \cdot$ Tsui-Kang Hsu ${ }^{2,6,7,8} \cdot$ Hsin-Wei Huang $^{9,10} \cdot$ Yi-Ming Huang ${ }^{1,2} \cdot$ Yi-Chang Chou $^{11,12}$. \\ Chen-Yu Chao ${ }^{13} \cdot$ Po-Chen Tseng ${ }^{14,15,16}$
}

Received: 4 July 2021 / Accepted: 26 October 2021 / Published online: 16 November 2021

(c) Springer-Verlag Italia S.r.l., part of Springer Nature 2021

\begin{abstract}
Aims To report the effect of simultaneous intravitreal dexamethasone (DEX) and aflibercept for the treatment of diabetic macular edema (DME).

Methods This retrospective analysis of an open-label, multicenter, consecutive case series included 102 eyes of 81 patients with DME. Patients were selected into two groups. The control group consisted of 50 eyes treated with aflibercept alone, and the combination group consisted of 52 eyes treated with simultaneous DEX implant and aflibercept injection. The primary endpoints were changes in best-corrected visual acuity (BCVA) and central retinal thickness (CRT) from baseline to month 6. The secondary endpoint was the interval of retreatment.

Results Baseline BCVA increased and CRT decreased at 6 months in both groups. Pseudophakic eyes in the combination group exhibited significantly greater BCVA improvement compared with phakic eyes $(p=0.031)$. Fewer intravitreal treatments were required for eyes treated with combination therapy than for those treated with aflibercept alone $(1.56 \pm 0.54$ vs. $4.04 \pm 1.26, p<.0001$ ), with a mean retreatment interval of $3.66 \pm 0.69$ months.

Conclusions Simultaneous intravitreal DEX and aflibercept achieved non-inferior improvement of visual and anatomic outcomes compared with aflibercept alone for DME, but exhibited a significantly longer treatment interval and superior visual outcome in pseudophakic eyes. This therapeutic approach is considered a valid strategy for treating DME in the era of COVID-19.
\end{abstract}

Keywords Aflibercept $\cdot$ Combination therapy $\cdot$ Dexamethasone $\cdot$ Diabetic macular edema

\section{Introduction}

The number of people diagnosed as having diabetes mellitus globally is estimated to grow to 700 million by the year 2045 [1]. In this population, diabetic retinopathy is the leading cause of visual loss, mainly as a result of the development of diabetic macular edema (DME) [2]. Therefore, managing DME and to reducing its treatment burden is crucial for retina specialists. Numerous studies have demonstrated the benefit of treating DME with intravitreal anti-vascular endothelial growth factor (VEGF) injections for improving

This article belongs to the topical collection Eye Complications of Diabetes, managed by Giuseppe Querques

Po-Chen Tseng

pochen.tseng@gmail.com

Extended author information available on the last page of the article visual acuity and reducing retinal thickening [3-5]. However, one limitation of this therapy is the frequent injections required to maintain efficacy. Since December 2019, the coronavirus disease (COVID-19) pandemic has had a major impact on healthcare systems around the world [6, 7]. Diabetic patients are considered at high risk for COVID-19 complications and should not be exposed to avoidable risks, including the frequent injections procedures [8]. Furthermore, large clinical trials have indicated that only $33-45 \%$ of patients with DME on anti-VEGF agents exhibit three lines or more of visual improvement on the Snellen chart [9-11]. The partial response to anti-VEGF agents is thought to be a result of the multifactorial etiology of DME [11-13].

In addition to anti-VEGF agents, intravitreal corticosteroids, such as the dexamethasone (DEX) intravitreal implant $0.7 \mathrm{mg}$ (Ozurdex, Allergan, Irvine, CA, USA), have been demonstrated to be effective in treating DME $[14,15]$. Thus, the combination of steroids and anti-VEGF agents may have 
synergistic effects in the treatment of DME because of their different pathophysiological targets. However, no widely accepted guidelines regarding combination therapy are available [12], and studies have provided only limited evidence for the use of licensed intravitreal anti-VEGF agent injections in combination with intravitreal steroid implants [16]. In this study, we compared the functional and anatomical outcomes of simultaneous intravitreal DEX and aflibercept versus an aflibercept monotherapy to treat patients with DME.

\section{Methods}

This was a multicenter study comprising five study sites. Institutional review board (IRB) approval was obtained through the individual IRBs at the participating institutes. This study was conducted in accordance with the Declaration of Helsinki.

Medical records of patients with a diagnosis of DME were reviewed for the period from January 1, 2020 to January 31, 2021. The inclusion criteria were as follow: (1) being aged 18 years or older; (2) having type 1 or 2 diabetes mellitus; (3) having DME causing visual loss, with a best-corrected visual acuity (BCVA) with Snellen equivalent of 20/400 to 20/40; and (4) having macular edema defined both clinically and by a central retinal thickness (CRT) of $>300 \mu \mathrm{m}$, measured using spectral-domain optical coherence tomography (OCT). The exclusion criteria were patients with (1) concomitant ocular disease that could cause macular edema and (2) a known history of glaucoma or past corticosteroid response. Patients who received anti-VEGF agents injection (within 3 months), panretinal laser photocoagulation (within 6 months) or focal/grid laser photocoagulation (within 3 months) before study entry were considered nontreatment naïve.

A total of 81 patients with DME, and 102 eyes were selected into two groups. The control group consisted of 50 eyes treated with aflibercept alone, and the combination group consisted of 52 eyes treated with simultaneous DEX implant and aflibercept injection. In every case, the baseline condition (at month 0 ) was examined before the first intravitreal treatment was performed. Each patient underwent a complete ophthalmologic examination including: a BCVA measurment, slit-lamp biomicroscopy, noncontact tonometer measurement, dilated fundus evaluation and photography, and spectral-domain OCT at month 0,1 month after each treatment, and month 6 .

The intravitreal injection was performed 3.5 or $4.0 \mathrm{~mm}$ posterior to the corneal limbus after topical anesthesia was applied, depending on the status of the lens. In the control group, patients received a $2 \mathrm{mg} / 0.05 \mathrm{~mL}$ injection of aflibercept alone, and those in the combination group received a $0.7 \mathrm{mg}$ intravitreal DEX implant followed by a $2 \mathrm{mg} / 0.05 \mathrm{~mL}$ injection of aflibercept in a different ocular quadrant during the same surgical session. Our retreatment criteria were a loss of BCVA of more than two Snellen chart lines and/or an increase in CRT of more than $100 \mu \mathrm{m}$. The primary endpoints were changes in BCVA and CRT from baseline to month 6 , and the secondary endpoint was the interval of retreatment. The criteria of adjuvant macular laser was in accordance with Early Treatment Diabetic Retinopathy Study guidelines [17] at intervals no shorter than 3 months from the first injection if deemed necessary by the evaluating investigator.

Considerable elevation in intraocular pressure (IOP) was defined as an increase in more than $5 \mathrm{mmHg}$ compared with the baseline level. The decision to initiate anti-glaucomatous medication was made along conventional lines according to the degree of IOP elevation and extent of glaucomatous optic neuropathy. The lens status was documented at every clinic visit, and the decision to perform cataract surgery was made through measurements of the level of vision in both the affected and unaffected eye and through consultation with the patient.

Statistical analysis was performed with SAS version 9.4 (SAS Institute, Inc., Cary, NC). Differences in baseline characteristics between the two groups were assessed using ChiSquared test or Fisher's exact test, and continuous variable were assessed using two sample $t$ test. Differences in outcome measures were analyzed using paired $t$ test. A paired $\mathrm{t}$ test, two sample $\mathrm{t}$ test, Chi-Squared test and Fisher's exact test were used to calculate significance. A $p$ value of less than 0.05 was considered significant.

\section{Results}

A total of 102 eyes from 81 patients diagnosed as having DME were included in the analysis; their demographic characteristics are presented in Table 1.

Age, gender, glycated hemoglobin (HbA1c), BCVA, and CRT at baseline did not differ between the two groups. Patients who received combination therapy had lower initial IOP than those in the control group $(16.3 \pm 3.1$ vs. $14.3 \pm 3.1 \mathrm{mmHg}, p=0.001$ ). A higher percentage of pseudophakic eyes was recorded in the combination group compared with the controls $(55.8 \%$ vs. $32 \%, p=0.018)$. The number of non-treatment naïve eyes were $26 / 50$ (52\%) in the control group, and 32/52 (61.5\%) in the combination group $(p=0.331)$ (Table 1). Baseline BCVA, OCT and final BCVA, OCT did not differ between treatment naïve and non-treatment naïve eyes in both groups (data not showed). Fewer intravitreal treatments were required during the study period for the combination group than the control group $(1.56 \pm 0.54$ vs. $4.04 \pm 1.26, p<0.0001)$, with a 
Table 1 Demographic characteristics and clinical data of all patients

\begin{tabular}{|c|c|c|c|c|c|}
\hline \multirow[t]{2}{*}{ Variable } & \multicolumn{2}{|c|}{ Control group $(n=50)$} & \multicolumn{2}{|c|}{ Combination group $(n=52)$} & \multirow[t]{2}{*}{$P$ value } \\
\hline & No. of eyes & $\%$ & No. of eyes & $\%$ & \\
\hline Age $($ mean $\pm S D)$ & $63.4 \pm 13.9$ & & $65.1 \pm 8.7$ & & 0.454 \\
\hline Gender (No. of patients) & $(n=40)$ & & $(n=41)$ & & 0.411 \\
\hline Female & 20 (14 patients) & $40.0(35.0)$ & 25 (21 patients) & $48.1(51.2)$ & $(0.141)$ \\
\hline Male & 30 (26 patients) & $60.0(65.0)$ & 27 (20 patients) & $51.9(48.8)$ & \\
\hline $\mathrm{HbA} 1 \mathrm{C} \%(\mathrm{mmol} / \mathrm{mol})(\operatorname{mean} \pm \mathrm{SD})$ & $\begin{array}{l}7.4 \pm 1.1 \% \\
57 \pm 12 \mathrm{mmol} / \mathrm{mol}\end{array}$ & & $\begin{array}{l}7.5 \pm 1.8 \% \\
58 \pm 20 \mathrm{mmol} / \mathrm{mol}\end{array}$ & & 0.633 \\
\hline Initial BCVA $(\log M A R)($ mean $\pm S D)$ & $0.63 \pm 0.33$ & & $0.64 \pm 0.35$ & & 0.820 \\
\hline Baseline CRT $(\mu \mathrm{m})$ & $420.6 \pm 88.6$ & & $433.8 \pm 118.7$ & & 0.524 \\
\hline Baseline IOP (mmHg) & $16.3 \pm 3.1$ & & $14.3 \pm 3.1$ & & 0.001 \\
\hline Treatment Naïve & & & & & 0.331 \\
\hline No & 26 & 52.0 & 32 & 61.5 & \\
\hline Yes & 24 & 48.0 & 20 & 38.5 & \\
\hline Lens status & & & & & 0.018 \\
\hline pseudophakia & 16 & 32.0 & 29 & 55.8 & \\
\hline phakia & 34 & 68.0 & 23 & 44.2 & \\
\hline Cataract surgery & & & & & 0.208 \\
\hline No & $32 / 34$ & 94.1 & $19 / 23$ & 82.6 & \\
\hline Yes & $2 / 34$ & 5.9 & $4 / 23$ & 17.4 & \\
\hline Macular laser & & & & & $<.0001$ \\
\hline No & 25 & 50.0 & 45 & 86.5 & \\
\hline Yes & 25 & 50.0 & 7 & 13.5 & \\
\hline Anti-glaucomatous medication & & & & & 0.247 \\
\hline No & 46 & 92.0 & 44 & 84.6 & \\
\hline Yes & 4 & 8.0 & 8 & 15.4 & \\
\hline \multicolumn{6}{|l|}{ Filtration surgery } \\
\hline No & 50 & 100.0 & 52 & 100 & \\
\hline Yes & 0 & 0.0 & 0 & 0 & \\
\hline No. of intravitral treatments $($ mean \pm SD) & $4.04 \pm 1.26$ & & $1.56 \pm 0.54$ & & $<.0001$ \\
\hline Retreatment interval (months, mean \pm SD) & $1.68 \pm 0.66$ & & $3.66 \pm 0.69$ & & $<.0001$ \\
\hline
\end{tabular}

$B C V A-$ Best-corrected visual acuity; $C R T$-Central retinal thickness; $I O P$-Intraocular pressure

mean retreatment interval of $3.66 \pm 0.69$ months. These eyes also had a significantly lower rate of adjuvant macular laser photocoagulation compared with those in the control group $(13.5 \%$ vs. $50 \%, p<0.001)$. The percentage of patients who required anti-glaucomatous medication and/or cataract surgery for the treated eye did not significantly differ between the two groups during the study period, and none of the eyes required filtration surgery.

Overall, BCVA improved in both groups after treatment. At baseline, the mean BCVA was $0.63 \pm 0.33$ logarithm of the minimum angle of resolution (logMAR) in the control group and $0.64 \pm 0.35 \log$ MAR in the combination group. At 6 months, the mean BCVA was $0.53 \pm 0.35 \log$ MAR in the control group and $0.55 \pm 0.53 \log$ MAR in the combination group ( $p=0.942$; Table 2 ). On comparison of the mean BCVA changes in each individual with respect to lens status, pseudophakic eyes in the combination group demonstrated greater improvement than the phakic eyes $(p=0.031$; Table 3). Pseudophakic eyes in the combination group showed a significant BCVA improvement from baseline throughout the study period. The monthly mean BCVA changes with respect to lens status is illustrated in Fig. 1. Spectral-domain OCT measurements exhibited a significant reduction in CRT at 6 months in both groups. The initial CRT was $420.6 \pm 88.6 \mu \mathrm{m}$ in the control group and $433.8 \pm 118.7 \mu \mathrm{m}$ in the combination group. At 6 months, the CRT was $311.5 \pm 91.1 \mu \mathrm{m}$ in the control group and $317.7 \pm 72.3 \mu \mathrm{m}$ in the combination group $(p=0.741$; Table 2). In the combination group, the monthly mean CRT changes did not differ between phakic eyes and pseudophakic eyes (Fig. 2). However, significantly reduced CRT from baseline was noted in the combination group but not in the control group throughout the study period. The mean IOP was $16.3 \pm 3.1 \mathrm{mmHg}$ at baseline in the control group and 
Table 2 Clinical outcomes at 6 months

\begin{tabular}{|c|c|c|c|c|c|c|c|}
\hline \multirow[t]{2}{*}{ Variable } & \multicolumn{3}{|c|}{ Control group $(n=50)$} & \multicolumn{3}{|c|}{ Combination group $(n=52)$} & \multirow{2}{*}{$\begin{array}{l}\text { Mean } \\
\text { change } \\
P \text {-value }\end{array}$} \\
\hline & Baseline & 6 months & $P$-value & Baseline & 6 months & $P$-value & \\
\hline BCVA (logMAR) & $0.63 \pm 0.33$ & $0.53 \pm 0.35$ & 0.016 & $0.64 \pm 0.35$ & $0.55 \pm 0.53$ & 0.013 & 0.942 \\
\hline $\mathrm{CRT}(\mu \mathrm{m})$ & $420.6 \pm 88.6$ & $311.5 \pm 91.1$ & $<0.001$ & $433.8 \pm 118.7$ & $317.7 \pm 72.3$ & $<0.001$ & 0.741 \\
\hline $\mathrm{IOP}(\mathrm{mmHg})$ & $16.3 \pm 3.1$ & $16.3 \pm 5.1$ & 0.948 & $14.3 \pm 3.1$ & $14.7 \pm 3.6$ & 0.264 & 0.505 \\
\hline
\end{tabular}

$B C V A-$ Best-corrected visual acuity; $C R T$-Central retinal thickness; $I O P$-Intraocular pressure

Table 3 BCVA (logMAR) outcomes at 6 months in terms of lens status

\begin{tabular}{|c|c|c|c|c|c|c|c|c|c|c|}
\hline \multirow[t]{2}{*}{ Variable } & \multicolumn{4}{|c|}{ pseudophakia $(n=45)$} & \multirow[t]{2}{*}{$P$-value } & \multicolumn{4}{|c|}{ phakia $(n=57)$} & \multirow[t]{2}{*}{$P$-value } \\
\hline & $n$ & Baseline & Mean change & $95 \% \mathrm{CI}$ & & $n$ & Baseline & Mean change & $95 \% \mathrm{CI}$ & \\
\hline Control group & 16 & $0.71 \pm 0.33$ & -0.118 & $-0.25-0.02$ & 0.086 & 34 & $0.58 \pm 0.33$ & -0.086 & $-0.19-0.01$ & 0.087 \\
\hline Combination group & 29 & $0.53 \pm 0.26$ & -0.135 & $-0.26-0.01$ & 0.031* & 23 & $0.78 \pm 0.41$ & -0.037 & $-0.25-0.17$ & 0.714 \\
\hline
\end{tabular}

$B C V A-$ Best-corrected visual acuity

$P$ values are for difference between pseudophakic eyes vs phakic eyes in both groups tested by paired t test

Fig. 1 The monthly mean bestcorrected visual acuity (BCVA) changes in terms of lens status. The combination group showed continuous improvements in BCVA during the first four months. Pseudophakic eyes in the combination group showed significant BCVA improvement from baseline

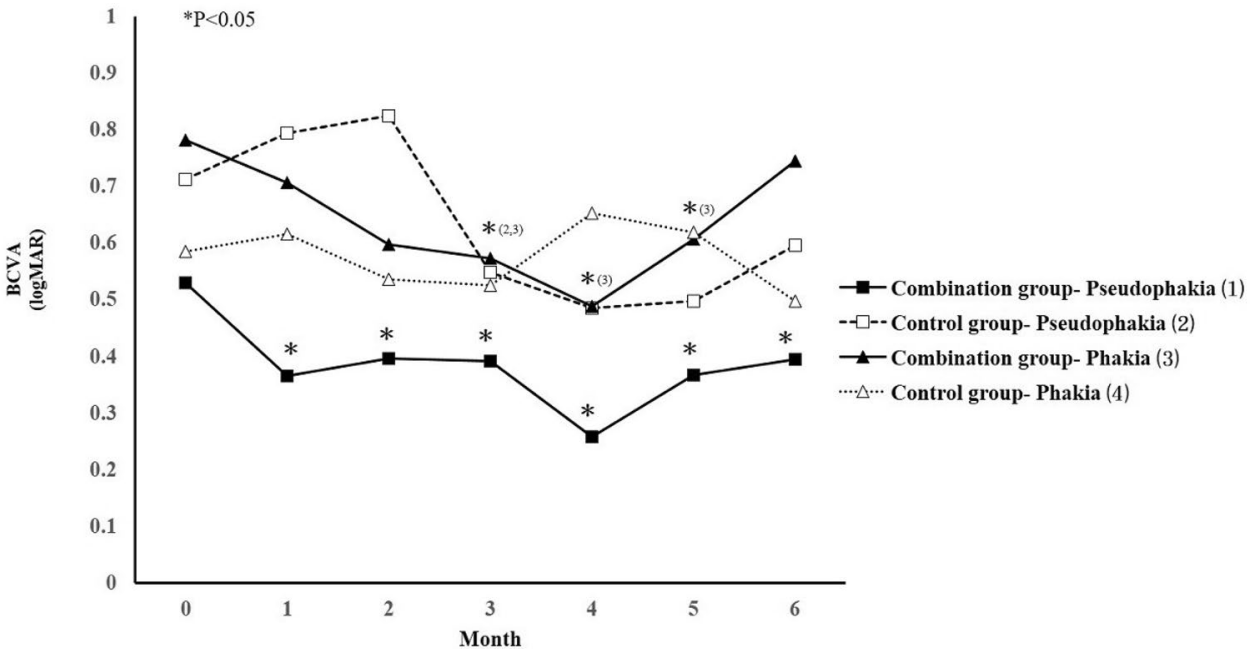

$14.3 \pm 3.1 \mathrm{mmHg}$ in the combination group $(\mathrm{p}=0.001)$. At 6 months, mean IOP was $16.3 \pm 5.1 \mathrm{mmHg}$ in the control group and $14.7 \pm 3.6 \mathrm{mmHg}$ in the combination group $(p=0.505)$, with four cases $(8 \%)$ in the control group and eight cases (15.4\%) in the combination group that were managed with topical anti-glaucomatous medications.

\section{Discussion}

The pathogenetic mechanisms of DME are complex and involve multiple factors. VEGF up-regulation and nonVEGF dependent inflammatory pathways contribute to the development of DME [18-20]. As a result, individual pharmacological treatments, including anti-VEGF agents and steroids, often do not result in a complete resolution of DME [12,13]. A strong rationale exists for combination therapy, but no widely accepted guidelines regarding the combined use of anti-VEGF agents and steroids have been proposed. To date, investigations regarding combination therapy have focused on eyes with persistent DME that were refractory to prior anti-VEGF injections [21-23]. Furthermore, the most studies did not use licensed antiVEGF agents and steroid implants and the majority of combination therapy comprised the combination of bevacizumab and triamcinolone [24-28]. Therefore, to address the gap between clinical practice and evidencebased references, we investigated the synergistic effects of 
Fig. 2 The monthly mean central retinal thickness (CRT) changes in terms of lens status. In the combination group, the monthly mean CRT changes did not differ between phakic eyes and pseudophakic eyes. Significantly reduced CRT from baseline was noted in the combination group but not in the control group throughout the study period

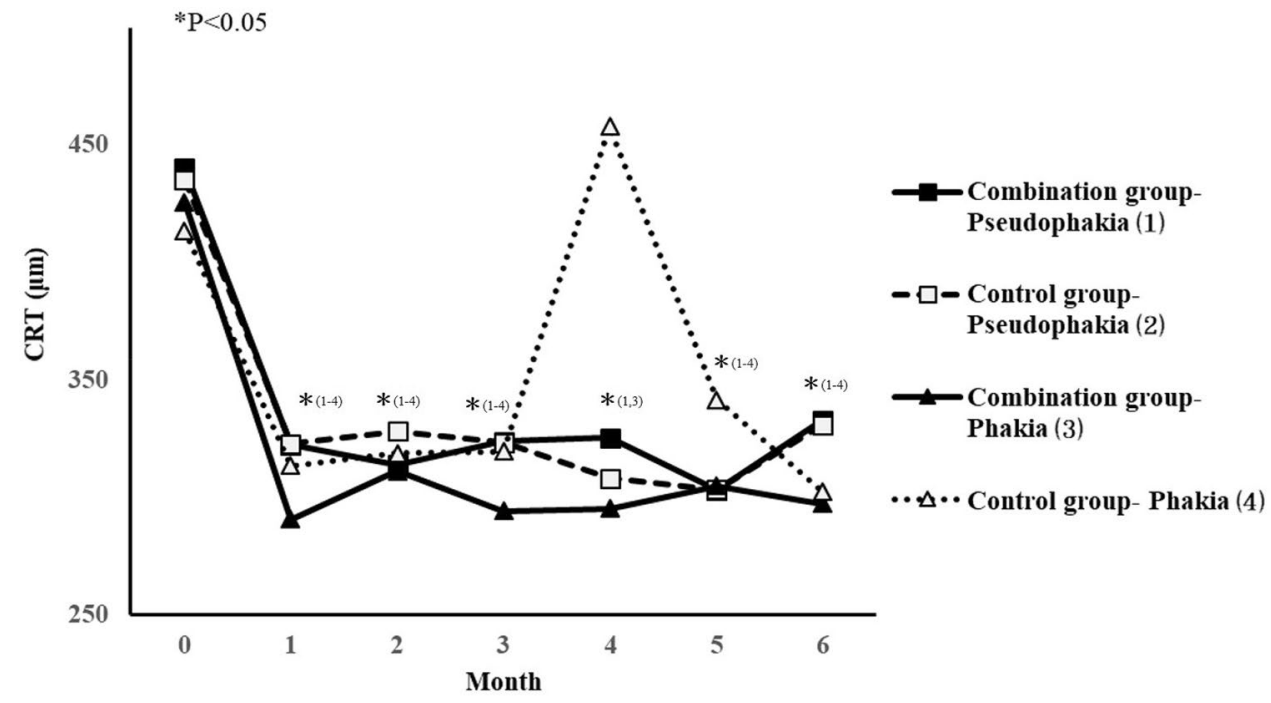

simultaneous intravitreal DEX and aflibercept as a primary treatment for DME.

Our results demonstrated that combination therapy was non-inferior in terms of BCVA improvement and CRT reduction compared with aflibercept monotherapy. When considering only pseudophakic eyes, we observed a greater improvement in BCVA changes in the combination group compared with phakic eyes. Despite Mehta et al. reported that visually marked cataract is unlikely to develop within the first 12 weeks of initiating DEX treatment [29]. Several studies have indicated that patients with preexisting cataracts exhibited no statistically significant functional improvement, but did display a significant anatomical improvement [30-32]. It is possible that some phakic eyes may have cataract progression caused by the DEX implant [21, 30, 31]. In our study, the eyes treated with combination therapy were more likely to undergo cataract surgery during the study period compared with eyes in the control group (17.4\% vs. $5.9 \%, p=0.208)$, although no significant difference was noted. This result indicated that the lens status may affect BCVA, and some patients may require cataract surgery later.

The total number of intravitreal treatments in the combination and control groups was $1.56 \pm 0.54$ and $4.04 \pm 1.26$, respectively. Previous studies have demonstrated that treatments with DEX implants must be applied more than once every 6 months, likely at 3-4 month intervals, to maintain a dry macula and retain favorable visual function [13, 14]. Therefore, whether combination therapy has synergistic effects in terms of the extension of treatment intervals remains unclear. In our study, the treatment interval of the combination group was extended to $3.66 \pm 0.69$ months. We demonstrated that using combination therapy provides continuous improvements in BCVA during the first four months, and significant BCVA improvement from baseline throughout the study period in pseudophakic eyes (Fig. 1).
Stabilization of CRT throughout the study period was noted in the combination group (Fig. 2). These results indicated that an initial combination of DEX and aflibercept may allow for a more rapid increase BCVA to the plateau and may induce a longer remission of DME than that achieved with anti-VEGF monotherapy [13]. As a result, applying combination therapy can reduce the treatment burden and reduce potential adverse events that may be associated with frequent anti-VEGF injection.

Laser photocoagulation was first recommended for treating DME in the 1985 Early Treatment Diabetic Retinopathy Study $[17,33]$ and represented the standard of care for the treatment of DME prior to the advent of anti-VEGF injections [34, 35]. Although no longer the standard treatment, macular laser therapy may still act as an adjuvant treatment because of its ability to reduce macular thickness and lower the required number of injections [36]. Our results demonstrated that eyes received combination treatment had a significantly lower rate of adjuvant macular laser photocoagulation compared with those in the control group.

A study compared anti-VEGF plus steroid with antiVEGF monotherapy as the primary treatment for DME; the results indicated a greater risk of increased IOP (Peto odds ratio [POR] 8.13, 95\% confidence interval [CI] 4.67- 14.16) and cataract development (POR 7.49, 95\% CI 2.87-19.60) in anti-VEGF plus steroid therapy [16]. However, the most studies have employed the combination of bevacizumab and triamcinolone. Steroid-related adverse events were less frequent in eyes treated with DEX compared with those treated with triamcinolone in the BEVORDEX study [15]. A significant elevation in IOP occurred in approximately $20 \%$ of eyes, and progression of cataract in $14.5 \%$ [14]. The increased IOP associated with the DEX implant was usually controlled with medication [13]. Similarly, in our study, $15.4 \%$ of eyes were managed 
with topical anti-glaucomatous medications, and $17.4 \%$ underwent cataract surgery. Nevertheless, steroid-related cataracts generally appear in the second year after steroid therapy, and cataract extraction is usually performed on three DEX implant-treated eyes [14, 37]. Therefore, the rate of cataract surgery in our patients is likely to increase later in the follow-up period. Despite the short-term study period, our results did not reveal a significantly higher rate of adverse effects compared with other studies when using DEX plus aflibercept as the primary treatment for DME.

We recognize some limitations of our analysis, including its short-term follow-up period and small sample size, which may have compromised the data analysis.

The study period was insufficient to evaluate differences in cataract extraction, and no standardized measurement of cataract development was performed. Therefore, a longer follow-up period is required to understand the long-term benefit of simultaneous DEX implant and aflibercept injection in the treatment of DME.

In conclusion, the ideal treatment approach for DME should achieve the following goals: improved BCVA, improved morphological changes in the macula maintained for a considerable duration, reduced adverse events, reduced treatment burden and costs, and increased treatment tolerance by patients [13]. Our study demonstrated that the application of simultaneous intravitreal DEX and aflibercept treatments achieved all the aforementioned goals and resulted in greater BCVA improvement in pseudophakic eyes than in phakic eyes. Furthermore, fewer patients in the combination group required macular laser therapy during the study period. Less or no energy laser applications may lead to a reduction in collateral damage [38] and preservation of long-term visual function. This therapeutic approach showed limited adverse effect during the study period, and exhibited a significantly longer treatment interval which is considered a valid strategy in the era of COVID-19.

Funding This study was supported by the Ministry of Science and Technology (MOST) (MOST 109-2314-B-075-029, and Taipei Veterans General Hospital (V110C-185).

\section{Declarations}

Conflict of interest The author(s) have no proprietary or commercial interest in any materials discussed in this article.

Ethical approval This was a multicenter study comprising five study sites. Institutional review board (IRB) approval was obtained through the individual IRBs at the participating institutes. This study was conducted in accordance with the Declaration of Helsinki.

Informed consent All participaints gave their informed consent prior to their inclusion in the study. Details that might disclose the identity of the subjects under study was omitted.

\section{References}

1. Saeedi P, Petersohn I, Salpea P et al (2019) Global and regional diabetes prevalence estimates for 2019 and projections for 2030 and 2045: Results from the International Diabetes Federation Diabetes Atlas, 9(th) edition. Diabetes Res Clin Pract 157:107843. https://doi.org/10.1016/j.diabres.2019.107843

2. Yau JW, Rogers SL, Kawasaki R et al (2012) Global prevalence and major risk factors of diabetic retinopathy. Diabetes Care 35(3):556-564. https://doi.org/10.2337/dc11-1909

3. Nguyen QD, Brown DM, Marcus DM et al (2012) Ranibizumab for diabetic macular edema: results from 2 phase III randomized trials: RISE and RIDE. Ophthalmology 119(4):789-801. https:// doi.org/10.1016/j.ophtha.2011.12.039

4. Korobelnik JF, Do DV, Schmidt-Erfurth U et al (2014) Intravitreal aflibercept for diabetic macular edema. Ophthalmology 121(11):2247-2254. https://doi.org/10.1016/j.ophtha.2014.05.006

5. Wells JA, Glassman AR, Ayala AR et al (2015) Aflibercept, bevacizumab, or ranibizumab for diabetic macular edema. N Engl J Med 372(13):1193-1203. https://doi.org/10.1056/NEJMoa1414 264

6. Denys P, Miere A, Colantuono D, Jung C, Souied EH (2021) Intravitreal injections during COVID-19 outbreak: protective measures, total duration of care and perceived quality of care in a tertiary retina center. Eur J Ophthalmol. https://doi.org/10.1177/ 11206721211003488

7. Bajka A, Wiest MRJ, Hamann T, Toro MD, Zweifel SA (2021) Assessment of patients' confidence regarding a new triage concept in a medical retina clinic during the first COVID-19 outbreak. Int J Environ Res Public Health. https://doi.org/10.3390/ijerph1811 5846

8. Iovino C, Peiretti E, Giannaccare G, Scorcia V, Carnevali A (2021) Evolving treatment paradigm in the management of diabetic macular edema in the Era of COVID-19. Front Pharmacol 12:670468. https://doi.org/10.3389/fphar.2021.670468

9. Gonzalez VH, Campbell J, Holekamp NM et al (2016) Early and long-term responses to anti-vascular endothelial growth factor therapy in diabetic macular edema: analysis of protocol i data. Am J Ophthalmol 172:72-79. https://doi.org/10.1016/j.ajo.2016. 09.012

10. Bressler NM, Beaulieu WT, Maguire MG et al (2018) Early response to anti-vascular endothelial growth factor and two-year outcomes among eyes with diabetic macular edema in protocol t. Am J Ophthalmol 195:93-100. https://doi.org/10.1016/j.ajo.2018. 07.030

11. Furino C, Boscia F, Reibaldi M, Alessio G (2021) Intravitreal therapy for diabetic macular edema: an update. J Ophthalmol 2021:6654168. https://doi.org/10.1155/2021/6654168

12. Al-Khersan H, Hariprasad SM, Salehi-Had H (2019) Dexamethasone and Anti-VEGF combination therapy for the treatment of diabetic macular edema. Ophthalmic Surg Lasers Imaging Retina 50(1):4-7. https://doi.org/10.3928/23258160-20181212-01

13. Amoaku WM, Saker S, Stewart EA (2015) A review of therapies for diabetic macular oedema and rationale for combination therapy. Eye (Lond) 29(9):1115-1130. https://doi.org/10.1038/ eye. 2015.110

14. Boyer DS, Yoon YH, Belfort R Jr et al (2014) Three-year, randomized, sham-controlled trial of dexamethasone intravitreal implant in patients with diabetic macular edema. Ophthalmology 121(10):1904-1914. https://doi.org/10.1016/j.ophtha.2014.04.024

15. Gillies MC, Lim LL, Campain A et al (2014) A randomized clinical trial of intravitreal bevacizumab versus intravitreal dexamethasone for diabetic macular edema: the BEVORDEX study. Ophthalmology 121(12):2473-2481. https://doi.org/10.1016/j. ophtha.2014.07.002 
16. Mehta H, Hennings C, Gillies MC, Nguyen V, Campain A, FraserBell S (2018) Anti-vascular endothelial growth factor combined with intravitreal steroids for diabetic macular oedema. Cochrane Database Syst Rev 4(4):011599. https://doi.org/10.1002/14651 858.CD011599.pub2

17. Early Treatment Diabetic Retinopathy Study Research Group (1987) Treatment techniques and clinical guidelines for photocoagulation of diabetic macular edema: early treatment diabetic retinopathy study report number 2. Ophthalmology 94:761-74. https://doi.org/10.1016/s0161-6420(87)33527-4

18. Klaassen I, Van Noorden CJ, Schlingemann RO (2013) Molecular basis of the inner blood-retinal barrier and its breakdown in diabetic macular edema and other pathological conditions. Prog Retin Eye Res 34:19-48. https://doi.org/10.1016/j.preteyeres.2013.02. 001

19. Schram MT, Chaturvedi N, Schalkwijk C et al (2003) Vascular risk factors and markers of endothelial function as determinants of inflammatory markers in type 1 diabetes: the EURODIAB prospective complications study. Diabetes Care 26(7):2165-2173. https://doi.org/10.2337/diacare.26.7.2165

20. Johnson MW (2009) Etiology and treatment of macular edema. Am J Ophthalmol 147(1):11-21.e11. https://doi.org/10.1016/j.ajo. 2008.07.024

21. Maturi RK, Glassman AR, Liu D et al (2018) Effect of adding dexamethasone to continued ranibizumab treatment in patients with persistent diabetic macular edema: a drcr network phase 2 randomized clinical trial. JAMA ophthalmology 136(1):29-38. https://doi.org/10.1001/jamaophthalmol.2017.4914

22. Maturi RK, Bleau L, Saunders J, Mubasher M, Stewart MW (2015) A 12-month, single-masked, randomized controlled study of eyes with persistent diabetic macular edema after multiple anti-vegf injections to assess the efficacy of the dexamethasonedelayed delivery system as an adjunct to bevacizumab compared with continued bevacizumab monotherapy. Retina (Philadelphia, Pa) 35(8):1604-1614. https://doi.org/10.1097/iae.0000000000 000533

23. Güler E, Totan Y, Betül Güragaç F (2017) Intravitreal bevacizumab and dexamethasone implant for treatment of chronic diabetic macular edema. Cutan Ocul Toxicol 36(2):180-184. https:// doi.org/10.3109/15569527.2015.1127254

24. Lim JW, Lee HK, Shin MC (2012) Comparison of intravitreal bevacizumab alone or combined with triamcinolone versus triamcinolone in diabetic macular edema: a randomized clinical trial. Ophthalmologica J Int d'ophtalmologie Int J Ophthalmol Zeitschrift fur Augenheilkunde 227(2):100-106. https://doi.org/ $10.1159 / 000331935$

25. Neto HO, Regatieri CV, Nobrega MJ et al (2017) Multicenter, randomized clinical trial to assess the effectiveness of intravitreal injections of bevacizumab, triamcinolone, or their combination in the treatment of diabetic macular edema. Ophthalmic Surg Lasers Imaging Retina 48(9):734-740. https://doi.org/10.3928/ 23258160-20170829-08

26. Ahmadieh H, Ramezani A, Shoeibi N, et al. (2008) Intravitreal bevacizumab with or without triamcinolone for refractory diabetic macular edema; a placebo-controlled, randomized clinical trial. Graefe's archive for clinical and experimental ophthalmology = Albrecht von Graefes Archiv fur klinische und experimentelle Ophthalmologie 246(4) 483-489. Doi: https://doi.org/10.1007/ s00417-007-0688-0

27. Soheilian M, Garfami KH, Ramezani A, Yaseri M, Peyman GA (2012) Two-year results of a randomized trial of intravitreal bevacizumab alone or combined with triamcinolone versus laser in diabetic macular edema. Retina (Philadelphia, Pa) 32(2):314-321. https://doi.org/10.1097/IAE.0b013e31822f55de

28. Yaseri M, Zeraati H, Mohammad K et al (2014) Intravitreal bevacizumab injection alone or combined with triamcinolone versus macular photocoagulation in bilateral diabetic macular edema; application of bivariate generalized linear mixed model with asymmetric random effects in a subgroup of a clinical trial. J Ophthalmic Vis Res 9(4):453-460. https://doi.org/10.4103/2008-322x. 150818

29. Mehta H, Fraser-Bell S, Nguyen V, Lim LL, Gillies MC (2018) Short-term vision gains at 12 weeks correlate with long-term vision gains at 2 years: results from the BEVORDEX randomised clinical trial of bevacizumab versus dexamethasone implants for diabetic macular oedema. Br J Ophthalmol 102(4):479-482. https://doi.org/10.1136/bjophthalmol-2017-310737

30. Maturi RK, Pollack A, Uy HS et al (2016) Intraocular pressure in patients with diabetic macular edema treated with dexamethasone intravitreal implant in the 3-year mead study. Retina (Philadelphia, Pa) 36(6):1143-1152. https://doi.org/10.1097/iae.0000000000 001004

31. Pacella F, Romano MR, Turchetti P et al (2016) An eighteenmonth follow-up study on the effects of Intravitreal Dexamethasone Implant in diabetic macular edema refractory to anti-VEGF therapy. Int J Ophthalmol 9(10):1427-1432. https://doi.org/10. 18240/ijo.2016.10.10

32. Al-Latayfeh M, Abdel Rahman M, Shatnawi R (2021) Outcome of single dexamethasone implant injection in the treatment of persistent diabetic macular edema after anti-VEGF treatment: real-life data from a tertiary hospital in jordan. Clin Ophthalmol (Auckland, NZ) 15:1285-1291. https://doi.org/10.2147/opth.S303670

33. Early Treatment Diabetic Retinopathy Study Research Group (1985) Photocoagulation for diabetic macular edema: early treatment diabetic retinopathy study report number 1 . Arch Ophthalmol 103:1796-806

34. Schmidt-Erfurth U, Garcia-Arumi J, Bandello F et al (2017) Guidelines for the Management of Diabetic Macular Edema by the European Society of Retina Specialists (EURETINA). Ophthalmol J Int d'ophtalmol Int J Ophthalmol Zeitschrift fur Augenheilkunde 237(4):185-222. https://doi.org/10.1159/000458539

35. Sheu SJ, Cheng CK, Kuo HK et al (2018) Treatment patterns in diabetic macular edema in Taiwan: a retrospective chart review. Clin Ophthalmol (Auckland, NZ) 12:2189-2198. https://doi.org/ 10.2147/opth.S170089

36. Distefano LN, Garcia-Arumi J, Martinez-Castillo V, Boixadera A (2017) Combination of anti-VEGF and laser photocoagulation for diabetic macular edema: a review. J Ophthalmol 2017:2407037. https://doi.org/10.1155/2017/2407037

37. Gillies MC, Sutter FK, Simpson JM, Larsson J, Ali H, Zhu M (2006) Intravitreal triamcinolone for refractory diabetic macular edema: two-year results of a double-masked, placebo-controlled, randomized clinical trial. Ophthalmology 113(9):1533-1538. https://doi.org/10.1016/j.ophtha.2006.02.065

38. Elman MJ, Qin H, Aiello LP et al (2012) Intravitreal ranibizumab for diabetic macular edema with prompt versus deferred laser treatment: three-year randomized trial results. Ophthalmology 119(11):2312-2318. https://doi.org/10.1016/j.ophtha.2012.08.022

Publisher's Note Springer Nature remains neutral with regard to jurisdictional claims in published maps and institutional affiliations. 


\section{Authors and Affiliations}

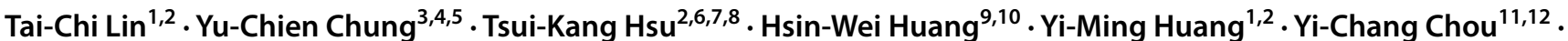 Chen-Yu Chao ${ }^{13} \cdot$ Po-Chen Tseng ${ }^{14,15,16}$}

1 Department of Ophthalmology, Taipei Veterans General Hospital, Taipei, Taiwan, Republic of China

2 Department of Ophthalmology, School of Medicine, National Yang Ming Chiao Tung University, Hsinchu, Taiwan, Republic of China

3 Department of Ophthalmology, Fu Jen Catholic University Hospital, Fu Jen Catholic University, New Taipei City, Taiwan, Republic of China

4 School of Medicine, Fu Jen Catholic University, New Taipei City, Taiwan, Republic of China

5 Graduate Institute of Business Administration, Fu Jen Catholic University, New Taipei City, Taiwan, Republic of China

6 Department of Ophthalmology, Cheng Hsin General Hospital, Taipei, Taiwan, Republic of China

7 Institue of Public Health, National Taiwan University, Taipei, Taiwan, Republic of China

8 Department of Life Science, Institute of Molecular Biology, Institute of Biomedical Science, National Chung Cheng University, Chiayi, Taipei, Taiwan, Republic of China
9 Department of Ophthalmology, Wan Fang Hospital, Taipei Medical University, Taipei, Taiwan, Republic of China

10 Graduate Institute of Clinical Medicine, College of Medicine, National Taiwan University, Taipei, Taiwan, Republic of China

11 Department of Education and Research, Taipei City Hospital, Taipei, Taiwan, Republic of China

12 Institute of Public Health, National Yang Ming Chiao Tung University, Hsinchu, Taiwan, Republic of China

13 Department of Life Science, Fu Jen Catholic University, New Taipei City, Taiwan, Republic of China

14 Department of Ophthalmology, Taipei City Hospital, Taipei, Taiwan, Republic of China

15 Department of Special Education, University of Taipei, Taipei, Taiwan, Republic of China

16 Department of Optometry, University of Kang-Ning, Taipei, Taiwan, Republic of China 